\title{
Audio-/Videorecording Clinic Visits for Patient's Personal Use in the United States: Cross-Sectional Survey
}

Paul J Barr ${ }^{1}$, MSc, PhD; Kyra Bonasia ${ }^{2}$, PhD; Kanak Verma ${ }^{2}$, MD, MPH; Michelle D Dannenberg ${ }^{1}$, MPH; Cameron $\mathrm{Yi}^{2}$, BA; Ethan Andrews ${ }^{3}$; Marisha Palm ${ }^{1}, \mathrm{MSc}, \mathrm{PhD}$; Kerri L Cavanaugh ${ }^{4,5}, \mathrm{MD}$, MHS; Meredith Masel ${ }^{6}$, MSW, $\mathrm{PhD}$; Marie-Anne Durand ${ }^{1}$, MSc, MPhil, PhD

\footnotetext{
${ }^{1}$ The Dartmouth Institute for Health Policy \& Clinical Practice, Geisel School of Medicine at Dartmouth, Dartmouth College, Lebanon, NH, United States

${ }^{2}$ Geisel School of Medicine at Dartmouth, Dartmouth College, Hanover, NH, United States

${ }^{3}$ University of St. Andrews, Fife, United Kingdom

${ }^{4}$ Vanderbilt Center for Effective Health Communication, Vanderbilt University Medical Center, Nashville, TN, United States

${ }^{5}$ Division of Nephrology and Hypertension, Department of Medicine, Vanderbilt University Medical Center, Nashville, TN, United States

${ }^{6}$ Oliver Center for Patient Safety \& Quality Healthcare, University of Texas Medical Branch, Galveston, TX, United States
}

\section{Corresponding Author:}

Paul J Barr, MSc, PhD

The Dartmouth Institute for Health Policy \& Clinical Practice

Geisel School of Medicine at Dartmouth

Dartmouth College

Williamson Translational Research Building, Level 5

One Medical Center Drive

Lebanon, NH, 03756

United States

Phone: 16036530863

Email: paul.j.barr@dartmouth.edu

\begin{abstract}
Background: Few clinics in the United States routinely offer patients audio or video recordings of their clinic visits. While interest in this practice has increased, to date, there are no data on the prevalence of recording clinic visits in the United States.

Objective: Our objectives were to (1) determine the prevalence of audiorecording clinic visits for patients' personal use in the United States, (2) assess the attitudes of clinicians and public toward recording, and (3) identify whether policies exist to guide recording practices in 49 of the largest health systems in the United States.
\end{abstract}

Methods: We administered 2 parallel cross-sectional surveys in July 2017 to the internet panels of US-based clinicians (SERMO Panel) and the US public (Qualtrics Panel). To ensure a diverse range of perspectives, we set quotas to capture clinicians from 8 specialties. Quotas were also applied to the public survey based on US census data (gender, race, ethnicity, and language other than English spoken at home) to approximate the US adult population. We contacted 49 of the largest health systems (by clinician number) in the United States by email and telephone to determine the existence, or absence, of policies to guide audiorecordings of clinic visits for patients' personal use. Multiple logistic regression models were used to determine factors associated with recording.

Results: In total, 456 clinicians and 524 public respondents completed the surveys. More than one-quarter of clinicians (129/456, $28.3 \%$ ) reported that they had recorded a clinic visit for patients' personal use, while $18.7 \%$ (98/524) of the public reported doing so, including $2.7 \%$ (14/524) who recorded visits without the clinician's permission. Amongst clinicians who had not recorded a clinic visit, $49.5 \%$ (162/327) would be willing to do so in the future, while $66.0 \%$ (346/524) of the public would be willing to record in the future. Clinician specialty was associated with prior recording: specifically oncology (odds ratio [OR] 5.1, 95\% CI 1.9-14.9; $P=.002$ ) and physical rehabilitation (OR 3.9, 95\% CI 1.4-11.6; $P=.01$ ). Public respondents who were male (OR 2.11, 95\% CI 1.26-3.61; $P=.005$ ), younger (OR 0.73 for a 10 -year increase in age, $95 \%$ CI $0.60-0.89 ; P=.002$ ), or spoke a language other than English at home (OR 1.99; $95 \%$ CI 1.09-3.59; $P=.02$ ) were more likely to have recorded a clinic visit. None of the large health systems we contacted reported a dedicated policy; however, 2 of the 49 health systems did report an existing policy 
that would cover the recording of clinic visits for patient use. The perceived benefits of recording included improved patient understanding and recall. Privacy and medicolegal concerns were raised.

Conclusions: Policy guidance from health systems and further examination of the impact of recordings-positive or negative-on care delivery, clinician-related outcomes, and patients' behavioral and health-related outcomes is urgently required.

(J Med Internet Res 2018;20(9):e11308) doi: 10.2196/11308

\section{KEYWORDS}

audiorecording; health care; health system; policy; United States; videorecording

\section{Introduction}

Up to $80 \%$ of health care information discussed verbally is forgotten by patients after their clinic visit [1-4]. Poor recall and understanding of medical concepts have been identified as significant barriers to self-management, a central component of the chronic care model [5-7]. The last decade has seen significant efforts to increase patient access to medical information. Mandated through meaningful use, clinics across the United States now offer patients an after-visit summary (AVS) [8]. AVS is a summary of the clinic visit generated from the electronic medical record (EMR) available via the web-based patient portal, which includes information on diagnoses, medication, allergies, clinician visited, and summary of visit [9]. OpenNotes moves beyond this basic summary, offering patients access to the clinical notes in their EMR [10,11]. Access to such written summaries of office visits is associated with improved adherence, patient and caregiver satisfaction, patient self-care, medical information recall, and preparedness for clinic visits [11-16]. However, there have been concerns about the accuracy and complexity of written summaries [12-14] and their low use by patients [15]. This issue is compounded by low levels of health literacy; $35 \%$ of Americans have below basic or basic health literacy [16].

An adjunct to written summaries is the sharing of clinic visit audiorecordings with patients [17-20]. With broad and growing access to smartphones, recording devices are now ubiquitous, and reports of patients recording their clinic visits, with or without permission, are emerging [17,20]. Over 40 years of research finds that patient access to recordings results in greater patient understanding and recall of visit information, reduced decisional regret, and increased patient satisfaction [21-23]. Audiorecordings are also highly utilized in the research context; in a scoping review of 33 studies (18 trials), $71 \%$ of patients listened to their recordings and $68 \%$ shared them with a family member or caregiver [21]. In addition, according to a recent analysis, recording of clinic visits would be guided by "wire-tapping" laws, which premises that patients in 39 states and the District of Columbia, can legally make recordings without explicit consent of the clinician; the remaining 11 states require all party consent [19].

A handful of clinics in the United States have recognized the potential of recording and routinely offer patients audiorecordings (video recordings in one case) of their visits [18]. Furthermore, educational sessions are now available to clinicians in return for Continuing Medical Education credit for training in what to do if they find a "secret recording of office visits by patients" [24]. Despite this increased interest in recording, no data exist on the prevalence of recording in clinical practice in the United States or the attitudes of clinicians and the public toward recording. Additionally, it is unclear whether US hospital systems have created guidance or policies for clinicians and patients regarding the practice of recording. Such data are essential to assess the acceptability of recording and the potential of this strategy to become more widely implemented.

In this paper, we report on the prevalence of sharing audiorecorded clinic visits in the United States, the attitudes of clinicians and the public toward recording, and health system policies to guide recording practices.

\section{Methods}

\section{Design}

We administered 2 parallel cross-sectional surveys in July 2017 to US-based clinicians and the public. We also surveyed 49 of the largest health systems in the US by phone and email. All methods and materials were approved by Dartmouth College's Committee for the Protection of Human Subjects (Study \#30345). The usability and technical functionality of both surveys was tested by the research team and colleagues before fielding the surveys. We used the Checklist for Reporting Results of Internet E-Surveys to report our findings (see Multimedia Appendix 1).

\section{Participants}

\section{United States Clinicians}

Clinicians were recruited and completed their surveys via SERMO (SERMO, Inc USA), the world's leading online community of physicians who participate in online medical market research studies. SERMO has over 800,000 verified licensed physician members. To be eligible for inclusion, clinicians (Doctor of Medicine or Doctor of Osteopathic Medicine) had to be currently practicing in the United States. In order to recruit a diverse sample of specialties, we included clinicians from the following 8 specialties: emergency medicine, general or family medicine, internal medicine, general surgery, obstetrics-gynecology, orthopedic surgery, physical rehabilitation, and psychiatry. A bulk email was sent to a random sample of panel members from each specialty, informing them that they may be eligible to take part in a study. This voluntary, open survey consisted of 3 required multiple choice questions (clinician's practice setting, years in practice, experiences of recording clinic visits) and 1 open response question assessing their views on patients having access to recordings (audio or video) of clinic visits and spanned over 1 screen (see Multimedia 
Appendix 2). Respondents could not review or change their answers or save responses if they wished to complete the survey later. Clinicians' sociodemographic data (gender, age, practice location converted to Rural Urban Commuting Area codes) were available via SERMO. All data were collected over a one-day time period from July 6 to July 7, 2017.

\section{United States Public}

Participants were recruited online using Qualtrics Panels (Qualtrics LLC, Provo, Utah, USA). Quotas were applied based on US census data (gender, race, ethnicity, and language other than English at home) to approximate the US adult population [25-28]. A bulk email was sent to a random sample of panel members based on quotas, informing potential respondents that they may be eligible to take part in a study; however, no information on the content of the survey was provided until members "clicked" on the survey link. Respondents receive "points" from Qualtrics for taking part, which can be redeemed for an incentive, for example, air miles, gift cards, etc. To be eligible for inclusion, individuals had to be $\geq 18$ years and reside in the United States. This voluntary, open survey consisted of 13 multiple choice questions (sociodemographics, experiences of recording clinic visits, and attitudes toward recording clinic visits) and 1 open response question assessing public views of recording clinic visits for patient's' personal use (see Multimedia Appendix 3). All questions were required and adaptive questioning was used. The survey included 14 items and spanned over 3 screens. Respondents could not review or change their answers or save responses if they wished to complete the survey later. Data were collected over a one-week time period from July 13 to July 19, 2017.

In both clinician and public surveys, the recruitment invitation included general information about the study (approximate length, purpose, and investigators) and a link to the anonymous and confidential survey. Participants consented by their decision to continue onto the survey. To increase the quality of data in both surveys, responses from individuals who completed the survey in less than one-third of the median completion time were excluded. Only completed questionnaires were analyzed.

\section{Health Care Systems}

We identified 49 of the largest health systems in the United States using the employed physician counts in IQVIA's OneKey reference data set and supplemented this with the information provided in the Agency for Healthcare Research and Quality (AHRQ) compendium of US Health Systems 2016 (see Multimedia Appendix 4) [29]. According to the AHRQ definition, "a health system includes at least one hospital and at least one group of physicians that provides comprehensive care (including primary and specialty care) who are connected with each other and with the hospital through common ownership or joint management." Health care system administrators, specifically those who worked in risk management or other relevant areas, were contacted by email and asked whether they have a recording policy at their health system. If such a policy existed, they were asked to describe it. Nonresponsive systems were contacted by telephone 1 week later. A maximum of 3 phone calls and emails were made, after which the system was considered a nonresponder.

\section{Data Analysis}

The prevalence of clinic visit recording and willingness to record was calculated for clinicians and the public. Multiple logistic regression analyses were conducted to identify factors associated with recording practices, including the history of recording, the history of covert recording (public respondents only), and willingness to record in the future. We planned to recruit a sample of 500 members of the public, which in a similarly sized probability sample would provide $95 \%$ CI of estimating the prevalence of recording in the population to within $\pm 4 \%$. We also aimed to sample at least 50 clinicians from each specialty, allowing for a minimum of 5 observations per parameter in the multiple logistic regression model [30]. Analyses were conducted using RStudio, V1.1.383 (RStudio, Boston, MA). We conducted a thematic analysis of all open-ended responses to identify salient themes reflecting the respondents' attitudes toward patient recordings, as well as any concerns or related benefits. Comments were independently reviewed, and $20 \%$ were double coded by 2 members of our research team (MAD, $\mathrm{KV}$ ). Finally, we categorized health systems as having an existing policy (and describing this policy), lacking an existing policy, or being unsure of their policies regarding clinic visit recordings.

\section{Results}

\section{Clinician Survey}

A total of 1472 clinicians were invited to complete the survey, of which 409 did not respond (see Figure 1). Of the remaining 1063 clinician, 456 clinicians completed the survey, while 599 were excluded as the quotas for these clinicians' specialties had been reached, and 8 clinicians were screened out (4 not currently in clinical practice and 4 declined). Respondents in the final sample ( $\mathrm{N}=456)$ came from 44 states and Washington DC. Survey completion took an average of 2 minutes 30 seconds. Of the included respondents, $61 \%$ had been practicing for more than 10 years, and the majority, $84 \%$, practiced at least half of their time in outpatient care (Table 1).

\section{Prevalence of Recording Practices}

Of 456 clinician respondents, 28.3\% (129/456; 95\% CI 24.2-32.7) reported that they had recorded a clinic visit for patients' personal use (Table 2). Of the remaining 327 clinicians who had not recorded, $49.5 \%$ (162/327, $95 \%$ CI 44.0-55.1) were willing to do so, while 50.5\% (165/327; 95\% CI 45.0-56.0) were not. Multiple logistic regression analyses revealed that only clinical specialty was associated with recording a visit in the past (Table 3): clinicians in oncology and physical rehabilitation were more likely to have had a visit recorded (reference category, general or family medicine), odds ratio (OR) 5.1 (95\% CI 1.9-14.9; $P=.002)$ and OR 3.9 (95\% CI $1.4-11.6 ; P=.01)$ respectively, and to be willing to be recorded by their patients in the future, OR $2.9(95 \%$ CI $1.2-7.4 ; P=.02)$ and OR 2.9 (95\% CI 1.2-7.6; $P=.03$ ), respectively (Table 3 ). Psychiatrist were also more willing to be recorded by their patients in the future, OR 2.7 (95\% CI 1.1-6.8; $P=.03)$. 
Figure 1. Overview of clinician and public survey participants.
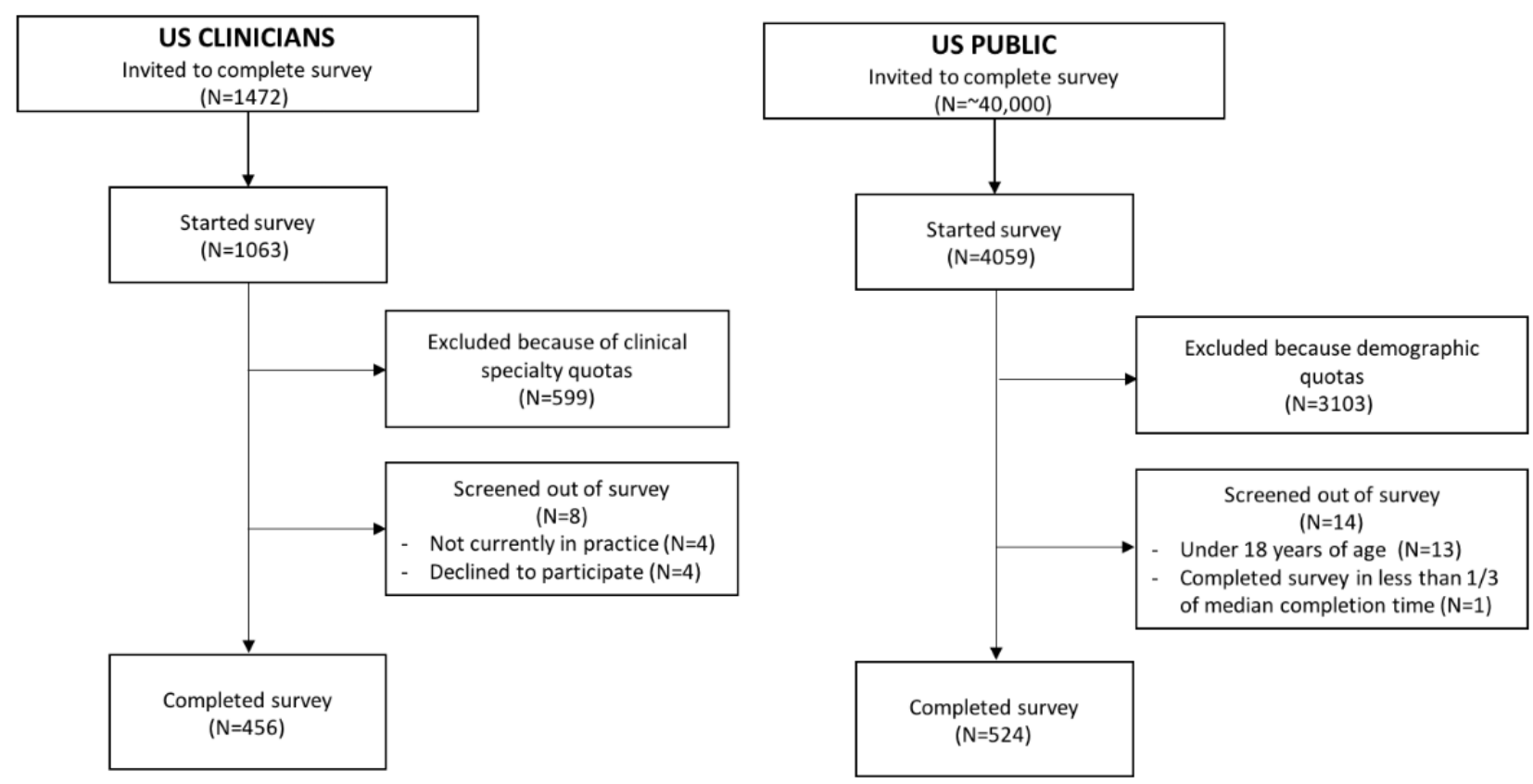

Table 1. Clinician respondent characteristics $(\mathrm{N}=456)$.

\begin{tabular}{|c|c|}
\hline Characteristics & $\mathrm{n}(\%)$ \\
\hline \multicolumn{2}{|l|}{ Gender } \\
\hline Female & 99 (21.7) \\
\hline Male & $291(63.8)$ \\
\hline Chose not to answer & $66(14.5)$ \\
\hline \multicolumn{2}{|l|}{ Years in practice } \\
\hline$<5$ & $63(13.8)$ \\
\hline $6-10$ & $113(24.8)$ \\
\hline $11-15$ & $84(18.4)$ \\
\hline$>15$ & $198(43.4)$ \\
\hline \multicolumn{2}{|l|}{ Clinical practice setting } \\
\hline All inpatient care & $19(4.2)$ \\
\hline Mostly inpatient care & $54(11.8)$ \\
\hline Half inpatient care, half outpatient care & $120(26.3)$ \\
\hline Mostly outpatient care & $151(33.1)$ \\
\hline All outpatient care & $112(24.6)$ \\
\hline \multicolumn{2}{|l|}{ Location } \\
\hline Urban & $426(93.4)$ \\
\hline Rural & $29(6.4)$ \\
\hline
\end{tabular}


Table 2. Clinician recording practices $(\mathrm{N}=456)$.

\begin{tabular}{llll}
\hline Specialty & $\begin{array}{l}\text { Recording history, } \mathrm{n}(\%) \\
\text { Yes, I have had a visit recorded } \\
\text { for a patient's personal use }\end{array}$ & $\begin{array}{l}\text { No, I have not had a visit } \\
\text { recorded, however I would } \\
\text { consider having a visit recorded } \\
\text { in the future }\end{array}$ & $\begin{array}{l}\text { No, I have not had a visit } \\
\text { recorded and I would not con- } \\
\text { sider having a visit recorded in } \\
\text { the future }\end{array}$ \\
\hline All $(\mathrm{n}=456)$ & $129(28.3)$ & $162(35.5)$ & $165(36.2)$ \\
Emergency medicine $(\mathrm{n}=51)$ & $11(21.6)$ & $22(43.1)$ & $18(35.3)$ \\
General or family practice $(\mathrm{n}=50)$ & $8(16.0)$ & $15(30.0)$ & $27(54.0)$ \\
General surgery $(\mathrm{n}=52)$ & $18(34.6)$ & $16(30.8)$ & $18(34.6)$ \\
Internal medicine $(\mathrm{n}=50)$ & $11(22.0)$ & $17(34.0)$ & $22(44.0)$ \\
Obstetrician-gynecologist $(\mathrm{n}=50)$ & $14(28.0)$ & $18(36.0)$ & $18(36.0)$ \\
Oncology $(\mathrm{n}=50)$ & $23(46.0)$ & $20(39.2)$ & $14(28.0)$ \\
Orthopedic surgery $(\mathrm{n}=51)$ & $11(21.6)$ & $17(34.0)$ & $20(39.2)$ \\
Physical rehabilitation $(\mathrm{n}=50)$ & $21(42.0)$ & $24(46.2)$ & $12(24.0)$ \\
Psychiatry $(\mathrm{n}=52)$ & $12(23.1)$ & $16(30.8)$
\end{tabular}

Table 3. Characteristics of clinicians associated with having had a clinic visit recorded for a patient's personal use in the past and willingness to have a clinic visit recorded for a patient's personal use.

\begin{tabular}{|c|c|c|}
\hline Factors & $\begin{array}{l}\text { History of recording clinic visit } \\
\text { for patient, } \mathrm{OR}^{\mathrm{a}}(95 \% \mathrm{CI})\end{array}$ & $\begin{array}{l}\text { Willingness to record clinic } \\
\text { visit in the future, OR }(95 \% \mathrm{CI})\end{array}$ \\
\hline Gender (reference: female) & $0.99(0.58-1.75)$ & $0.77(0.44-1.30)$ \\
\hline Years in practice ( 5 year increments) & $1.03(0.82-1.29)$ & $0.83(0.66-1.04)$ \\
\hline \multicolumn{3}{|c|}{ Setting (reference: $1 / 2$ inpatient, $1 / 2$ outpatient) } \\
\hline Mostly inpatient & $0.84(0.38-1.78)$ & $1.21(0.57-2.64)$ \\
\hline Mostly outpatient & $0.83(0.46-1.49)$ & $0.76(0.43-1.34)$ \\
\hline Location (reference: urban) & $1.25(0.48-2.99)$ & $0.66(0.29-1.50)$ \\
\hline \multicolumn{3}{|c|}{ Specialty (reference: general or family practice) } \\
\hline Emergency medicine & $1.72(0.58-5.37)$ & $2.10(0.85-5.31)$ \\
\hline General surgery & $2.85(0.97-9.00)$ & $1.75(0.67-4.64)$ \\
\hline Internal medicine & $1.12(0.34-3.68)$ & $1.65(0.67-4.14)$ \\
\hline Obstetrician-gynecologist & $2.25(0.81-6.68)$ & $1.88(0.80-4.52)$ \\
\hline Oncology & $5.11(1.93-14.90)$ & $2.90(1.19-7.35)$ \\
\hline Orthopedic surgery & $1.37(0.41-4.66)$ & $1.10(0.41-2.95)$ \\
\hline Physical rehabilitation & $3.91(1.43-11.63)$ & $2.90(1.16-7.59)$ \\
\hline Psychiatry & $1.69(0.59-5.09)$ & $2.75(1.14-6.84)$ \\
\hline
\end{tabular}

${ }^{\mathrm{a} O R}$ : odds ratio. 
Table 4. General clinician and public attitudes toward patient access to audiorecordings of clinic visits.

\begin{tabular}{lll}
\hline Views on patient access to recordings of clinic visits & Physicians, $\mathrm{n}(\%)$ & General public, $\mathrm{n}(\%)$ \\
\hline Total respondents who shared general attitude in open-ended response & $377(81.8)$ & $459(87.8)$ \\
Supportive of patient access to recordings & $136(36.1)$ & $301(65.6)$ \\
Supportive of case-by-case basis of recordings & $34(9.0)$ & $11(2.4)$ \\
Concerned about patient access to recordings & $183(48.5)$ & $90(19.6)$ \\
Uncertain, had never previously considered patient access to recordings & $16(4.2)$ & $23(5.0)$ \\
Neutral, no opinion toward patient access to recordings & $8(2.1)$ & $34(57.4)$ \\
\hline
\end{tabular}

Clinicians'Views of Sharing Recordings of Clinic Visits

In the open-ended responses to their views on providing clinic recordings to patients $(\mathrm{n}=377), 170$ clinicians were supportive of recording, 183 were concerned about recording, while the remaining clinicians were neutral or uncertain (Table 4). Proposed benefits included improved information recall and understanding, the ability for clinicians to use the audiorecordings for documentation purposes, and clinical education:

\section{There are legitimate reasons to do it at times! Maybe for someone who is afraid they will not remember or for someone who could not be there. \\ I would welcome the idea if this replaces writing long notes on EMR. \\ It might be useful (in the right setting) as a tool for peer feedback on patient interaction.}

Privacy concerns and risk of medicolegal use by patients emerged as the most common concerns among clinicians:

The recording of office visits would be used by lawyers to twist our words against us in court.

However, some clinicians considered it protective:

If I detect a potential litigious patient I would ask if the visit could be recorded.

Clinicians also expressed concerns regarding a negative impact on the patient-clinician interaction through potentially less "open" consultations and whether patients would use recordings:

...I'd be skeptical of how much patients would actually view the videos or benefit from the service.

\section{United States Public Survey}

Approximately 40,000 individuals were invited to take part in the survey, of which 4059 responded (see Figure 1). Of those 4059 individuals, 524 completed the entire survey, while 3103 were excluded as quotas for these individuals were reached and 14 individuals were screened out (13 were under 18 years and 1 respondent completed the survey in less than one-third of the median completion time: 1 minute 48 seconds). Respondents in the final sample $(n=524)$ belonged from 48 states. The sociodemographic characteristics of the respondents approximated that of the US population (Table 5).

\section{Prevalence of Recording Practices}

Of the public respondents, $15.6 \%$ (82/524; 95\% CI 12.6-19.0) reported audio or video recording a clinic visit with permission, while $2.7 \%$ (14/524; 95\% CI 1.5-4.4) did so secretly (Table 6). Additionally, $19.3 \%$ respondents (101/524; 95\% CI 16.0-22.9) reported that they were aware of a family member or friend who reported recording a clinic visit, of which $60.4 \%(61 / 101 ; 95 \%$ CI 49.2-69.1) asked permission and $25.7 \%$ (26/101; 95\% CI 17.6-35.4) did not. Finally, 58.6\% (307/524; 95\% CI 54.2-62.8) reported that they would consider recording a visit in the future with permission of the clinician and 7.4\% (39/524; 95\% CI 5.3-10.0) without the clinician's permission, while $37.4 \%$ (196/524) were not interested in recording a clinic visit.

In a multiple logistic regression analysis, individuals who reported having recorded a clinic visit with the permission of their provider were more likely to be male, OR 2.11 (95\% CI $1.26-3.61 ; P=.005$ ); to be younger, OR 0.73 (95\% CI 0.60-0.89; $P=.002)$ per 10 years increase in age; and to speak a language other than English at home, OR 1.99 (95\% CI 1.09-3.59; $P=.02$; Table 7). While $63 \%$ of general public respondents were interested in recording a clinic visit in the future, older adults (OR $0.88,95 \%$ CI $0.78-0.99$ per 10 years increase in age) and those with a lower level of education (OR $0.58,95 \%$ CI $0.38-0.89$ ) were less likely to be interested in recording a clinic visit for their personal use. This analysis did not reveal any demographic factors that were predictive of individuals having recorded a clinic visit covertly (all $P>.15$ ).

\section{Public Views of Sharing Recordings of Clinic Visits}

In the open-ended responses ( $\mathrm{n}=459), 312$ were supportive of recording and 90 were concerned about recordings, while the remaining public comments were considered neutral or uncertain (Table 6). Similar themes regarding concerns and potential benefits associated with recordings emerged from public respondents when compared to clinician respondents. The most common positive theme was the potential for recordings to improve patient recall and understanding of medical information:
I would like this option since I'm not very knowledgeable about medical terms and if I ask questions during the visit it might go over my head. If I can play it back, I would better absorb what I need to know or if I missed something, I can hear it again...

Additionally, a small proportion of respondents believed that recordings could be used for medicolegal purposes and to improve clinician recall of visit information:

It allows for patients and doctors to look back on the visit for information they might have missed. 
Concerns were less common in the public sample, but included privacy concerns, "These recordings could fall into the wrong hands"; unclear benefit to patient of recordings, "I'm not really sure what the point would be to have my clinic visits recorded..."; and possible impact on the visit, "recording my visits may inhibit my interaction with the health professional."

\section{Health Care System Recording Policies}

When 49 of the largest health care organizations in the United States were asked in August 2017 about the existence of a policy regarding patient recording care systems, 47 responded to our request (Multimedia Appendix 4). Of the responses, 22 reported no formal policy, 13 were unsure if they had a policy, 4 stated that such policies would be left to the individual clinics, 6 said that the policy would be physician dependent, and 2 reported an existing policy that would cover patient requests for audiorecordings or videorecordings of the clinic visit (Table 8). Of the clinics that reported an existing policy that could be applied, the Henry Ford Health System, Michigan stated that patients' audiorecordings or videorecordings and photographs must comply with privacy laws and their institutional policy.

Table 5. Public respondent characteristics $(\mathrm{N}=524)$.

\begin{tabular}{|c|c|}
\hline Characteristics & $\mathrm{n}(\%)$ \\
\hline \multicolumn{2}{|l|}{ Gender } \\
\hline Female & $255(48.7)$ \\
\hline Male & $262(50.0)$ \\
\hline Other & $7(1.3)$ \\
\hline \multicolumn{2}{|l|}{ Age (years) } \\
\hline $18-40$ & $304(58.0)$ \\
\hline $41-60$ & $152(29.0)$ \\
\hline$>60$ & $68(13.0)$ \\
\hline \multicolumn{2}{|l|}{ Education } \\
\hline High school degree or less & $124(23.7)$ \\
\hline Some college or college degree or equivalent & $313(59.7)$ \\
\hline Postgraduate degree (Masters, $\mathrm{PhD}$, or professional) & $73(13.9)$ \\
\hline Other & $14(2.7)$ \\
\hline \multicolumn{2}{|l|}{ Hispanic origin } \\
\hline Yes & $66(12.6)$ \\
\hline No & $458(87.4)$ \\
\hline \multicolumn{2}{|l|}{ Race } \\
\hline American Indian or Alaska Native & $4(1.0)$ \\
\hline Asian & $21(4.0)$ \\
\hline Black or African American & $75(14.3)$ \\
\hline Native Hawaiian or other Pacific Islander & $0(0.0)$ \\
\hline White & $412(78.6)$ \\
\hline Other & $12(2.3)$ \\
\hline \multicolumn{2}{|l|}{ Language other than English spoken at home? } \\
\hline Yes & $104(19.8)$ \\
\hline No & $420(80.2)$ \\
\hline
\end{tabular}

The Henry Ford Health System patient photographs and video recordings policy allows for recording, but consent must be attained first and the recording will be stored in the EMR, which patients can request access to. The Mayo Clinic, Minnesota stated that "with their consent, patients, families and staff may be photographed or video recorded by families and/or visitors at Mayo facilities for the purpose of education for continuing care of the patient following discharge," but that no other forms of photography or video are allowed. 
Table 6. Public recording practices $(\mathrm{N}=524)$.

\begin{tabular}{|c|c|}
\hline Survey item & Respondent, $\mathrm{n}(\%)$ \\
\hline \multicolumn{2}{|c|}{ Have you ever recorded (audio or video) a clinic visit with your doctor or health professional? } \\
\hline Yes, and I asked for permission first & $82(15.6)$ \\
\hline Yes, and I did so secretly (without asking permission first) & $14(2.7)$ \\
\hline No, I have never recorded a clinic visit & $431(82.3)$ \\
\hline \multicolumn{2}{|l|}{ Would you consider recording a clinic visit with a doctor or another health professional? } \\
\hline Yes, I would consider recording with the permission of the doctor & $307(58.6)$ \\
\hline Yes, I would consider secretly recording (without the permission of the doctor) & $39(7.4)$ \\
\hline No, I have no interest in recording a clinic visit & $196(37.4)$ \\
\hline \multicolumn{2}{|l|}{ Are recordings (audio or video) of patient clinic visits routinely offered in your clinic? } \\
\hline Yes & $51(9.7)$ \\
\hline No & $262(50.0)$ \\
\hline Not sure & $211(40.3)$ \\
\hline \multicolumn{2}{|c|}{ Do you know a family member or friend who has recorded (audio or video) a visit with a doctor or health professional? } \\
\hline Yes & $101(19.3)$ \\
\hline No & $423(80.7)$ \\
\hline \multicolumn{2}{|c|}{ Did the family member or friend ask permission before recording the clinic visit? ( $n=101)$} \\
\hline Yes & $61(60.4)$ \\
\hline No & $26(25.7)$ \\
\hline Not sure & $14(13.9)$ \\
\hline
\end{tabular}

Table 7. Characteristics of the public associated with a history of recording a clinic visit and with an interest in recording a clinic visit for their own personal use, with or without permission from their doctor or health professional.

\begin{tabular}{lllc}
\hline Characteristics & $\begin{array}{l}\text { History of recording with permission, } \\
\mathrm{OR}^{\mathrm{a}}(95 \% \mathrm{CI})\end{array}$ & $\begin{array}{l}\text { History of recording covertly, } \\
\text { OR }(95 \% \mathrm{CI})\end{array}$ & $\begin{array}{l}\text { Interest in recording, } \\
\text { OR }(95 \% \mathrm{CI})\end{array}$ \\
\hline Age $\quad$ & $0.97(0.95-0.99)$ & $1.01(0.97-1.05)$ & $0.99(0.98-0.999)$ \\
$\quad \begin{array}{l}\text { Increase of 1 year } \\
\quad \text { Increase of 10 years }\end{array}$ & $0.73(0.60-0.89)$ & $1.10(0.73-1.62)$ & $0.88(0.78-0.99)$ \\
Gender (reference: female) & $2.11(1.26-3.61)$ & $1.55(0.48-5.41)$ & $1.22(0.85-1.78)$ \\
Education (reference: some college or college degree) & $1.12(0.61-2.01)$ & $0.60(0.09-2.36)$ & $0.58(0.38-0.89)$ \\
$\quad$ High school or less & $0.97(0.41-2.08)$ & $\mathrm{N} / \mathrm{A}^{\mathrm{b}}$ & $0.75(0.44-1.29)$ \\
$\quad$ Postgraduate degree & $0.76(0.43-1.36)$ & $0.39(0.11-1.45)$ & $1.07(0.69-1.66)$ \\
Race (white non-Hispanic vs everybody else) & $1.99(1.09-3.59)$ & $1.49(0.36-5.45)$ & $1.54(0.93-2.60)$ \\
Language other than English spoken at home & & &
\end{tabular}

${ }^{\mathrm{a} O R}$ : odds ratio.

${ }^{\mathrm{b}} \mathrm{N} / \mathrm{A}$ : not applicable. 
Table 8. Responses from 49 large health care organizations in the United States.

\begin{tabular}{ll}
\hline Response & Organizations, $\mathrm{n}(\%)$ \\
\hline Has a policy & $2(4)$ \\
No policy & 2(45) \\
Policy is up to individual facilities & 6(8) \\
Policy is up to individual physicians & $12)$ \\
Unknown & 13(26.5) \\
No Response & $2(4)$ \\
\hline
\end{tabular}

\section{Discussion}

\section{Principal Findings}

In this study, the first to explore the prevalence of clinic recording in the United States, we found that one-third of surveyed clinicians have recorded a clinic visit for a patient's personal use and that half of those who have not recorded would be willing to do so in the future. Approximately one-fifth of the public reported recording a visit in the past and two-thirds would consider recording a visit in the future. Oncologists and physical rehabilitation clinicians were most likely to have recorded a visit. Members of the public who were younger, male, or spoke a language other than English at home were most likely to have recorded. Clinicians and patients commented on the benefits of recording, including improved recall and understanding. However, clinicians also reported privacy and medicolegal concerns. None of the 49 large health systems that we spoke to reported a dedicated policy or guidance for clinicians or patients on the practice of sharing clinic visit recordings; two reported that this would fall under an existing guideline.

\section{Limitations}

This project is not without limitations. Since we used online panels to recruit clinicians and members of the general public, it is not possible to create a response rate. By ensuring that our respondent samples approximated census data with regard to age, gender, education, and language spoken at home, we reduced the potential impact of selection bias. Additionally, the representativeness of data gathered from internet panels has been shown to be comparable to that from probability-based general population samples [31]. We were not able to determine who instigated the recording for those who have recorded or whether this practice is routine in clinicians who reported sharing a recording in the past; however, $10 \%$ (51/524) of public respondents did report that this practice was routine at their clinic. Focusing on a sample of the public, rather than a sample of patients, may underrepresent the prevalence of recording occurring in health care as it includes a range of respondents, many of whom will have limited experience with health systems.

\section{Comparison with Prior Work}

The current project supports previous findings that patients are beginning to "press record" during clinic visits [17-18,20]. Similar to previous studies, clinicians' views on recordings were mixed. The benefits of increased understanding, recall, and the possibility of better self-management were tempered by medicolegal and privacy concerns. Despite these concerns, a significant proportion of clinicians have shared recordings or are willing to do so in the future.

Reports of covert recording in this project $(14 / 524,2.7 \%)$ are much lower than those reported in a previous study, where $15 \%$ of United Kingdom public respondents reported this practice [20]. This difference may be due to the high risk of selection bias in the UK survey, where a small convenience survey $(n=128)$ was administered following a radio talk show discussing pros and cons of covertly recording clinic visits. Yet, in the present survey, $25.7 \%$ (26/101) of respondents who were aware of a family member or friend recording a visit reported that this was done covertly.

Only clinician specialty was associated with recording practice and intention to record, with almost half of oncologists and physical rehabilitation clinicians reporting that they had shared a recording in the past. Higher rates of recording in oncology may be due to the emotional nature of a cancer diagnosis and complex treatment plans. Additionally, most previous research on the use of recordings in health care has taken place in oncology settings [21]. While physical rehabilitation is less studied, the benefit of recordings in this population of patients has been documented in an ongoing case study (Barr; PJB, unpublished data, February 2017). Clinicians from general or family practice were the least likely $(8 / 50,16 \%)$ and least willing to record $(15 / 50,30 \%)$. Barriers to recording use among these clinicians may be due to the significant clinical informatics challenges reported, including the volume of clinical reminders and computerized patient record system alerts and time needed to input EMR notes [32]. Coupled with the diverse nature of patients and severity of conditions, it is not surprising that general and family clinicians are least likely to record. Yet, for these reasons, audiorecording could be beneficial in primary care, especially with advances in speech-to-text software that could assist with documentation at the point-of-care (see Implications).

Public respondents who spoke a language other than English at home were more likely to report recording a clinic visit. This may be a strategy to mitigate poor communication of health care information commonly reported by patients with low English proficiency [33-35]. Younger individuals also reported higher rates of recording, which may reflect their comfort with technology and greater likelihood of having a smartphone [36]. It is unclear why male patients are more likely to record than females, but this finding supports our previous survey in the UK [20]. The differences do not appear to be due to smartphone access or use [36]. It may be that because men are reported to 
delay health seeking compared with women, their clinic visits may be related to more complex problems where recording would be helpful [37]. Men may also be more likely to record in order to report back to women in their lives (eg, wife, sister, mother). Whereas women traditionally manage their family's health care [38] and as such may feel less need to record and share their visit. Alternatively, they could simply be more willing to ask permission to record. Further investigation of individual differences in recording practice by minority groups and gender is required.

Further investigation of individual differences in recording practice by minority groups and gender is required.

\section{Implications}

With no clear policies, it appears that clinicians and patients are leading the way on the implementation of recording in health care delivery. Through the lens of the "Diffusion of Innovation" model, the recent increase in the use of recordings is not unexpected as it meets the principles required for successful diffusion outlined by Berwick [39]: (1) the need for change is apparent; (2) the innovation is compatible with adopters' values; (3) it is simple and flexible; (4) it is trialable; and (5) it is observable. The need to improve the transparency and communication of medical information in clinics is evident from recent policies, such as meaningful use [8] and advances in OpenNotes [10]. Furthermore, 40 years ago, recording of clinic visits was complicated, involving impractical technology; today, it is simple, so much so that clinics have many ways in which to implement recording practices. In a recent case study, clinics that routinely offered recordings used a range of approaches including patient phones, digital recorders, and clinicians' computers to audiorecord and electronic tablets to videorecord visits [18]. It appears that we are at the early adopter stage of recording practice. The dissemination of innovations in health care has a tipping point of $15 \%-20 \%$ after which it is difficult to stop [40]. Recording and sharing of clinic visits may have reached this point.

With significant developments in fields of artificial intelligence and conversational analytics, health care will be transformed in the next decade; $35 \%$ of health care organizations plan to leverage artificial intelligence within 2 years and more than half intend to do so within 5 years [41-43]. Audiorecorded clinic data holds significant potential to tackle some of the major challenges we face today at lower costs, such as clinician documentation burden, patient recall of visit information, and improved patient-centered communication [44]. Highly accurate speech-to-text systems will enable real-time visit documentation [32]; patients and clinicians will once again be able to talk without the barrier of a computer. Our research group is developing a recording system that will use machine learning to tag key information from the clinic visit and link this to credible lay information for patients and their caregivers: Audio-Personal Health Library (PaHL) [45]. We hypothesize that Audio-PaHL will improve patient recall and understanding of visit information, resulting in improved self-management and a better health care experience via improved care coordination and higher satisfaction [18].

\section{Conclusions and Relevance}

US clinicians and public are taking the lead on sharing clinic visit recordings, while policy makers lag behind. Policy guidance for clinics and further examination of the impact of recordings on clinical practice - both positive and potentially unforeseen negative_-are urgently required.

\section{Acknowledgments}

We would like to acknowledge the input of Professors Glyn Elwyn and Martha Bruce for their thoughtful feedback on survey development and sampling strategy.

Identification of health systems in this project based was supported in part by AHRQ's Comparative Health System Performance Initiative under Grant \#1U19HS024075, which studies how health care delivery systems promote evidence-based practices and patient-centered outcomes research in delivering care. The findings and conclusions in this article are those of the author(s) and do not necessarily reflect the views of AHRQ.

The statements, findings, conclusions, views, and opinions contained and expressed in this article are based in part on data obtained under license from Quintiles IQVIA information services: OneKey reference data set 2010-2017, IQVIA Health Incorporated all rights reserved. The statements, findings, conclusions, views, and opinions contained and expressed herein are not necessarily those of IQVIA Health Incorporated or any of its affiliated or subsidiary entities.

\section{Conflicts of Interest}

PJB, KB, KV, MDD, CY, EA, MP, KLC, and MM have no financial conflicts to declare. PJB leads a research initiative "Open Recordings" investigating the applications and implications of audio and video recording clinical visits, including the development of Open Recording Automated Logging System and Audio-PaHL funded by the Gordon and Betty Moore Foundation and National Library of Medicine, respectfully. MAD receives consulting income from EBSCO Health and may receive royalties in the future. She is also a consultant for Access Community Health Network.

\section{Multimedia Appendix 1}

Checklist for Reporting Results of Internet E-Surveys (CHERRIES).

[PDF File (Adobe PDF File), 106KB-Multimedia Appendix 1] 


\section{Multimedia Appendix 2}

National recording survey: clinicians.

[PDF File (Adobe PDF File), 57KB-Multimedia Appendix 2]

\section{Multimedia Appendix 3}

National recording survey: general public.

[PDF File (Adobe PDF File), 71KB-Multimedia Appendix 3]

\section{Multimedia Appendix 4}

Overview of health care systems.

[PDF File (Adobe PDF File), 41KB-Multimedia Appendix 4]

\section{References}

1. Watson PWB, McKinstry B. A systematic review of interventions to improve recall of medical advice in healthcare consultations. J R Soc Med 2009 Jun;102(6):235-243 [FREE Full text] [doi: 10.1258/jrsm.2009.090013] [Medline: 19531618]

2. Kessels RPC. Patients' memory for medical information. J R Soc Med 2003 May;96(5):219-222 [FREE Full text] [Medline: $12724430]$

3. Jansen J, Butow PN, van WJCM, van DS, Devine RJ, Heeren TJ, et al. Does age really matter? Recall of information presented to newly referred patients with cancer. J Clin Oncol 2008 Nov 20;26(33):5450-5457. [doi:

10.1200/JCO.2007.15.2322] [Medline: 18936478 ]

4. Ley P. Memory for medical information. Br J Soc Clin Psychol 1979 Jun;18(2):245-255. [Medline: 454984]

5. Wagner EH. Chronic disease management: what will it take to improve care for chronic illness? Eff Clin Pract 1998;1(1):2-4 [FREE Full text] [Medline: 10345255]

6. Hibbard JH, Greene J. What the evidence shows about patient activation: better health outcomes and care experiences; fewer data on costs. Health Aff (Millwood) 2013 Feb;32(2):207-214. [doi: 10.1377/hlthaff.2012.1061] [Medline: 23381511]

7. Bayliss EA, Ellis JL, Steiner JF. Barriers to self-management and quality-of-life outcomes in seniors with multimorbidities. Ann Fam Med 2007;5(5):395-402 [FREE Full text] [doi: 10.1370/afm.722] [Medline: 17893380]

8. HealthIT. 2012. Providing Clinical Summaries to Patients after Each Office Visit: A Technical Guide With contributions from Internet URL: https://www.healthit.gov/sites/default/files/measure-tools/avs-tech-guide.pdf [accessed 2018-08-18] [WebCite Cache ID 711Dt88V2]

9. Emani S, Healey M, Ting DY, Lipsitz SR, Ramelson H, Suric V, et al. Awareness and Use of the After-Visit Summary Through a Patient Portal: Evaluation of Patient Characteristics and an Application of the Theory of Planned Behavior. J Med Internet Res 2016 Apr 13;18(4):e77 [FREE Full text] [doi: 10.2196/jmir.5207] [Medline: 27076485]

10. Delbanco T, Walker J, Bell SK, Darer JD, Elmore JG, Farag N, et al. Inviting patients to read their doctors' notes: a quasi-experimental study and a look ahead. Ann Intern Med 2012 Oct 2;157(7):461-470 [FREE Full text] [doi: 10.7326/0003-4819-157-7-201210020-00002] [Medline: 23027317]

11. Wright E, Darer J, Tang X, Thompson J, Tusing L, Fossa A, et al. Sharing Physician Notes Through an Electronic Portal is Associated With Improved Medication Adherence: Quasi-Experimental Study. J Med Internet Res 2015 Oct 08;17(10):e226 [FREE Full text] [doi: 10.2196/jmir.4872] [Medline: 26449757]

12. Federman AD, Sanchez-Munoz A, Jandorf L, Salmon C, Wolf MS, Kannry J. Patient and clinician perspectives on the outpatient after-visit summary: a qualitative study to inform improvements in visit summary design. J Am Med Inform Assoc 2017 Apr 01;24(e1):e61-e68. [doi: 10.1093/jamia/ocw106] [Medline: 27497793]

13. Friedman AJ, Cosby R, Boyko S, Hatton-Bauer J, Turnbull G. Effective teaching strategies and methods of delivery for patient education: a systematic review and practice guideline recommendations. J Cancer Educ 2011 Mar;26(1):12-21. [doi: 10.1007/s13187-010-0183-x] [Medline: 21161465]

14. Kripalani S. Clinical summaries for hospitalised patients: time for higher standards. BMJ Qual Saf 2017 May;26(5):354-356. [doi: 10.1136/bmjqs-2016-005826] [Medline: 27435191]

15. Pavlik V, Brown AE, Nash S, Gossey JT. Association of patient recall, satisfaction, and adherence to content of an electronic health record (EHR)-generated after visit summary: a randomized clinical trial. J Am Board Fam Med 2014;27(2):209-218 [FREE Full text] [doi: 10.3122/jabfm.2014.02.130137] [Medline: 24610183]

16. Kutner M, Greenberg E, Jin Y, Paulsen C. The Health Literacy of America's Adults: Results From the 2003 National Assessment of Adult Literacy (NCES 2006-483). US Department of Education, National Center for Education Statistics 2006 Sep:1-76 [FREE Full text]

17. Tsulukidze M, Grande SW, Thompson R, Rudd K, Elwyn G. Patients covertly recording clinical encounters: threat or opportunity? A qualitative analysis of online texts. PLoS One 2015;10(5):e0125824 [FREE Full text] [doi: 10.1371/journal.pone.0125824] [Medline: 25933002] 
18. Barr PJ, Dannenberg MD, Ganoe CH, Haslett W, Faill R, Hassanpour S, et al. Sharing Annotated Audio Recordings of Clinic Visits With Patients-Development of the Open Recording Automated Logging System (ORALS): Study Protocol. JMIR Res Protoc 2017 Jul 06;6(7):e121 [FREE Full text] [doi: 10.2196/resprot.7735] [Medline: 28684387]

19. Elwyn G, Barr PJ, Castaldo M. Can Patients Make Recordings of Medical Encounters? What Does the Law Say? JAMA 2017 Aug 08;318(6):513-514. [doi: 10.1001/jama.2017.7511] [Medline: 28692707]

20. Elwyn G, Barr PJ, Grande SW. Patients recording clinical encounters: a path to empowerment? Assessment by mixed methods. BMJ Open 2015 Aug 11;5(8):e008566 [FREE Full text] [doi: 10.1136/bmjopen-2015-008566] [Medline: 26264274]

21. Tsulukidze M, Durand M, Barr PJ, Mead T, Elwyn G. Providing recording of clinical consultation to patients - a highly valued but underutilized intervention: a scoping review. Patient Educ Couns 2014 Jun;95(3):297-304. [doi: 10.1016/j.pec.2014.02.007] [Medline: 24630697]

22. Scott JT, Entwistle VA, Sowden AJ, Watt I. Giving tape recordings or written summaries of consultations to people with cancer: a systematic review. Health Expect 2001 Sep;4(3):162-169 [FREE Full text] [Medline: 11493322]

23. McClement SE, Hack TF. Audio-taping the oncology treatment consultation: a literature review. Patient Educ Couns 1999 Mar;36(3):229-238. [Medline: 14528558]

24. Tilburt, J. Medscape, ACP Ethics Case Studies. 2017. Secret Recordings of Office Visits by Patients URL: https://www. medscape.org/viewpublication/30131 [accessed 2018-08-22] [WebCite Cache ID 71rXFB13j]

25. Howden L, Meyer J. 2010 Census Briefs. 2011. Age and Sex Composition URL: https://www.census.gov/prod/cen2010/ briefs/c2010br-03.pdf [accessed 2018-08-21] [WebCite Cache ID 71qP2fTxD]

26. Humes K, Jones N, Ramirez R. 2010 Census Briefs. 2011. Overview of Race and Hispanic Origin URL: https://www. census.gov/prod/cen2010/briefs/c2010br-02.pdf [accessed 2018-08-21] [WebCite Cache ID 71qP8vkAJ]

27. US Census Bureau. 2010. Language Use Internet URL: http://www.census.gov/hhes/socdemo/language/ [accessed 2018-08-21] [WebCite Cache ID 71qPBetZU]

28. Ryan C, Bauman K. 2016. Educational Attainment in the United States Population Characteristics Current Population Reports Internet URL: https://www.census.gov/content/dam/Census/library/publications/2016/demo/p20-578.pdf [accessed 2018-08-21] [WebCite Cache ID 71qPF6wZ6]

29. Agency for Healthcare Research and Quality. 2017. Compendium of US Health Systems, 2016 URL: https://www.ahrq.gov/ chsp/compendium/index.html [accessed 2018-08-22] [WebCite Cache ID 71rVlwRBb]

30. Vittinghoff E, McCulloch CE. Relaxing the rule of ten events per variable in logistic and Cox regression. Am J Epidemiol 2007 Mar 15;165(6):710-718. [doi: 10.1093/aje/kwk052] [Medline: 17182981]

31. Liu H, Cella D, Gershon R, Shen J, Morales LS, Riley W, et al. Representativeness of the Patient-Reported Outcomes Measurement Information System Internet panel. J Clin Epidemiol 2010 Nov;63(11):1169-1178 [FREE Full text] [doi: 10.1016/j.jclinepi.2009.11.021] [Medline: 20688473]

32. Farmer MM, Rose DE, Rubenstein LV, Canelo IA, Schectman G, Stark R, et al. Challenges facing primary care practices aiming to implement patient-centered medical homes. J Gen Intern Med 2014 Jul;29 Suppl 2:S555-S562 [FREE Full text] [doi: 10.1007/s11606-013-2691-y] [Medline: 24715394]

33. Divi C, Koss RG, Schmaltz SP, Loeb JM. Language proficiency and adverse events in US hospitals: a pilot study. Int J Qual Health Care 2007 Apr;19(2):60-67. [doi: 10.1093/intqhc/mzl069] [Medline: 17277013]

34. Karliner LS, Kim SE, Meltzer DO, Auerbach AD. Influence of language barriers on outcomes of hospital care for general medicine inpatients. J Hosp Med 2010;5(5):276-282. [doi: 10.1002/jhm.658] [Medline: 20533573]

35. Karliner LS, Auerbach A, Nápoles A, Schillinger D, Nickleach D, Pérez-Stable EJ. Language barriers and understanding of hospital discharge instructions. Med Care 2012 Apr;50(4):283-289 [FREE Full text] [doi: 10.1097/MLR.0b013e318249c949] [Medline: 22411441]

36. Pew Research Center Internet. 2018 Feb 05. Demographics of Mobile Device Ownership and Adoption in the United States URL: http://www.pewinternet.org/fact-sheet/mobile/ [accessed 2018-08-21] [WebCite Cache ID 71qQK9YRy]

37. Thompson AE, Anisimowicz Y, Miedema B, Hogg W, Wodchis WP, Aubrey-Bassler K. The influence of gender and other patient characteristics on health care-seeking behaviour: a QUALICOPC study. BMC Fam Pract 2016 Mar 31;17:38 [FREE Full text] [doi: 10.1186/s12875-016-0440-0] [Medline: 27036116]

38. AARP. Caregiving in the U.S. 2015 Report URL: https://www.aarp.org/content/dam/aarp/ppi/2015/ caregiving-in-the-united-states-2015-report-revised.pdf [accessed 2018-08-27] [WebCite Cache ID 71yhHk7bp]

39. Berwick DM. Disseminating innovations in health care. JAMA 2003 Apr 16;289(15):1969-1975. [doi: 10.1001/jama.289.15.1969] [Medline: 12697800 ]

40. Rogers EM. Lessons for guidelines from the diffusion of innovations. Jt Comm J Qual Improv 1995 Jul;21(7):324-328. [Medline: 7581733]

41. Rosenthal D, Sokolowski R. Voice-enabled, structured medical reporting. IEEE Intell. Syst 1998 Jan;13(1):70-73. [doi: $10.1109 / 5254.653227]$

42. Sensmeier J. Harnessing the power of artificial intelligence. Nurs Manage 2017 Nov;48(11):14-19. [doi: 10.1097/01.NUMA.0000526062.69220.41] [Medline: 29023284] 
43. Sullivan T. Healthcare IT News. 2017. Half of hospitals to adopt artificial intelligence within 5 years | Healthcare IT News URL: http://www.healthcareitnews.com/news/half-hospitals-adopt-artificial-intelligence-within-5-years [accessed 2018-05-02] [WebCite Cache ID 71rZRr5pe]

44. Ommaya A, Cipriano P, Hoyt D, Horvath K, Tang P, Paz H, et al. Care-Centered Clinical Documentation in the Digital Environment: Solutions to Alleviate Burnout. NAM Perspectives 2018 Jan 29;8(1):1-13 [FREE Full text] [doi: 10.31478/201801c]

45. Open Recordings. URL: http://www.openrecordings.org/ [accessed 2018-08-27] [WebCite Cache ID 71yhe6yTd]

\section{Abbreviations}

AHRQ: Agency for Healthcare Research \& Quality

AVS: after-visit summary

EMR: electronic medical record

OR: odds ratio

Edited by G Eysenbach; submitted 15.06.18; peer-reviewed by J Ryan, S Emani; comments to author 04.07.18; revised version received 19.07.18; accepted 19.07.18; published 12.09.18

Please cite as:

Barr PJ, Bonasia K, Verma K, Dannenberg MD, Yi C, Andrews E, Palm M, Cavanaugh KL, Masel M, Durand MA

Audio-/Videorecording Clinic Visits for Patient's Personal Use in the United States: Cross-Sectional Survey

J Med Internet Res 2018;20(9):e11308

URL: http://www.jmir.org/2018/9/e11308/

doi: $\underline{10.2196 / 11308}$

PMID: 30209029

CPaul J Barr, Kyra Bonasia, Kanak Verma, Michelle D Dannenberg, Cameron Yi, Ethan Andrews, Marisha Palm, Kerri L Cavanaugh, Meredith Masel, Marie-Anne Durand. Originally published in the Journal of Medical Internet Research (http://www.jmir.org), 12.09.2018. This is an open-access article distributed under the terms of the Creative Commons Attribution License (https://creativecommons.org/licenses/by/4.0/), which permits unrestricted use, distribution, and reproduction in any medium, provided the original work, first published in the Journal of Medical Internet Research, is properly cited. The complete bibliographic information, a link to the original publication on http://www.jmir.org/, as well as this copyright and license information must be included. 